\title{
THE
}

\section{Healthy Sleep Leads to Improved Nutrition and Exercise in College Females}

\author{
Sue K. Adams \\ University of Rhode Island, suekadams@uri.edu \\ Elizabeth Dimond \\ University of Rhode Island \\ Matthew J. Delmonico \\ University of Rhode Island, delmonico@uri.edu \\ Emily Sylvester \\ University of Rhode Island
}

Epllow this and additional works at: https://digitalcommons.uri.edu/nfs_facpubs

The University of Rhode Island Faculty have made this article openly available.

Please let us know how Open Access to this research benefits you.

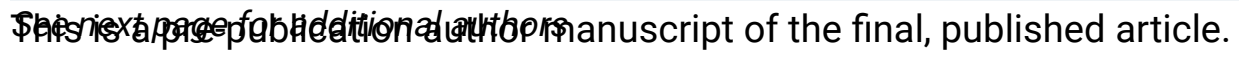

Terms of Use

This article is made available under the terms and conditions applicable towards Open Access Policy Articles, as set forth in our Terms of Use.

\section{Citation/Publisher Attribution}

Adams S, Cook E, Domos C, Dimond E, Delmonico MS, Lofgren IE. 2020. Healthy Sleep Leads to Improved Nutrition and Exercise in College Females. Topics in Clinical Nutrition. 35(2):135-143. doi: 10.1097/ TIN.0000000000000206 Available at: http://dx.doi.org/10.1097/TIN.0000000000000206

This Article is brought to you for free and open access by the Nutrition and Food Sciences at DigitalCommons@URI. It has been accepted for inclusion in Nutrition and Food Sciences Faculty Publications by an authorized administrator of DigitalCommons@URI. For more information, please contact digitalcommonsgroup@uri.edu. 


\section{Authors}

Sue K. Adams, Elizabeth Dimond, Matthew J. Delmonico, Emily Sylvester, Chelsea Accetta, Carley Domos, and Ingrid E. Lofgren

This article is available at DigitalCommons@URI: https://digitalcommons.uri.edu/nfs_facpubs/90 


\begin{abstract}
Diet, sleep quality and exercise are important determinants of physical, mental and emotional health. College students are particularly vulnerable to impaired health, as they experience multiple unique stressors associated with college life that impact their ability to engage in healthy sleep, diet and exercise habits. Our results found that exercise significantly mediated the association between sleep quality and diet. Improved sleep habits may increase a young woman's ability and desire to exercise, thus impacting her diet and nutrition. Findings suggest that clinicians can use a person's motivation in any one domain, or multiple domains, to impact other health domains.
\end{abstract}

Key Words: Sleep, Diet, Exercise, Young adults 


\section{INTRODUCTION}

Sleep, nutrition, and physical activity are essential components in facilitating physical, mental, emotional and social health. ${ }^{1}$ Healthy People 2020, a national initiative in the United States aimed at health promotion across the lifespan, emphasizes the importance of sleep health, good nutrition, and physical activity across the lifespan. Specifically, Healthy People 2020 proposes to increase the proportion of adolescents and adults receiving sufficient sleep and engaged in healthy eating and physical activity. ${ }^{2}$ Although it is clear how increasing physical activity leads to increased sleep and energy demands, and better sleep may lead to more energy for physical activity, the link between sleep, physical activity and diet, particularly in females, remains a gap in knowledge and requires further investigation. ${ }^{3}$

\section{Sleep in Young Adults}

Though sleep research is robust in adolescents and older adult populations, much less is known about sleep in young adults, ${ }^{4,5}$ specifically those who experience the unique demands of college life and females. ${ }^{3}$ In 2016 , just over $41 \%$ of $18-24$ year old young adults living in the United States were enrolled in a 2-year or 4-year college or university, an increase of 37\% since $2002 .{ }^{6}$ A number of factors make college students particularly vulnerable to sleep disruption and deprivation, including increased academic demands, increased social engagement, technology use, irregular schedules, stress, noise, and challenges with time management. ${ }^{4,7}$ Furthermore, college students experience a natural biological shift in circadian rhythms, making them more prone to want to go to sleep later in the evening and wake up later in the morning. ${ }^{8}$ This circadian shift is often incompatible with the demands of daily life, such as waking up for early morning classes, athletic practices and work. Moreover, given a gender bias that affects research in both community and clinical samples, even less is known about women's circadian rhythms 
compared to men. It has been reported that women tend to be mis- and/or underdiagnosed for sleeping disorders. ${ }^{3}$ Researchers have also found that college females also experience more overall sleep disturbance than college males. ${ }^{9}, 10$

Despite needing an average of $81 \frac{1}{4}$ hours of sleep per night to feel well rested, ${ }^{8,11}$ the typical college student reports sleeping between 6-7 hours per night. ${ }^{4,8}$ Young adults exhibit symptoms of various sleep disorders, with the most common symptoms falling in the area of insomnia and circadian rhythm disorders. ${ }^{12,13}$ College students who experience inadequate sleep may also experience magnified difficulties concentrating in school and at work, ${ }^{14}$ negative moods and depressive symptoms, and decreased social functioning. ${ }^{4,}{ }^{15}$ Lund and colleagues ${ }^{4}$ also reported that poorer sleepers were prone to increased rates of physical illness when compared to well-rested peers. Additionally, diet and physical activity are two additional factors that can dramatically change when students transition from living at home for high school to living on a college campus, where they experience much more independence. ${ }^{16,17}$ Increased choice over food options and increased freedom in how to structure time can lead college students to "test the waters," sometimes making choices that impair rather than promote their overall health, specifically their diet, exercise and sleep patterns. ${ }^{5,18}$

\section{Diet and Sleep}

The association between sleep and diet is complex and not fully understood. Previous research has shown associations between sleep and diet. Sleep duration is inversely associated with body mass index (BMI) ${ }^{5}$ and future weight gain ${ }^{19}$ and diet quality is positively associated

with sleep duration and regular sleep patterns. ${ }^{14,20}$ However, there is little evidence to suggest if diet predicts sleep or vice versa. 
There is some evidence that a balanced diet with foods in moderation can improve sleep quality ${ }^{14}$ and St. Onge et al. ${ }^{21}$ summarizes evidence that specific foods such has milk, fatty fish and specific fruits may promote sleep. Additionally, Peuhkuri et al. ${ }^{14}$ examined whether diet quality or individual dietary components like macronutrients or micronutrients were associated with duration or sleep quality and determined that previous research has not provided "concrete clinical evidence". The association between meal patterns and sleep could be partially due to more energy-dense and less nutrition foods typically seen with more snacking and consumption of the majority of calories in the evening. ${ }^{14}$ Alternatively, some evidence suggests that inadequate sleep may increase appetite, due to decreased leptin and increased ghrelin concentrations. ${ }^{5,19,22}$ Additionally, other proposed mechanisms include less sleep can lead to less physical activity and an increase in energy dense foods. ${ }^{5}$ A number of studies have compared single meals versus meals eaten the day before, ${ }^{14,22}$ rather than looking at overall intake and diet. It is critical to look at habitual dietary intake impact on sleep duration and quality as that reflects the "real world setting" more accurately.

\section{Exercise and Sleep}

Exercise has a significant impact on sleep quality and sleep regulation in adults, but research in college students is limited and has primarily focused on young adults who are "good sleepers" or physically fit college athletes. ${ }^{23-25}$ In adults, evidence suggests that increased physical activity facilitates homeostatic sleep regulation and stabilizes the circadian system by reducing the need for daytime naps. ${ }^{24,26}$ Increased physical activity can also improve general psychological functioning, thus reducing anxiety and depressive symptoms that interfere with sleep. ${ }^{8}$ 
The limited research on sleep in college students has revealed that exercise and physical activity are associated with better sleep. ${ }^{23,27,28}$ For example, Brand and colleagues ${ }^{23}$ found that in a sample of 434 adolescents including athletes and non-athletes, male athletes reported better overall sleep habits, increased slow wave sleep, reduced light sleep and shorter sleep onset latency than controls. A second study of 38 adolescents also confirmed that regular, nonvigorous exercise is to improved sleep in non-athlete adolescents. ${ }^{23,27}$ Conversely, better sleep efficiency has been positively associated with physical activity in college students. ${ }^{28}$ Just as the relationnship between exercise and sleep lacks research on young adults, so does the relationship between exercise and diet.

\section{Exercise and Diet}

Lifestyle choices made during the transitional time between adolescence and young adulthood can negatively influence health. ${ }^{18,29}$ This is especially true in college students, in whom the documented trend is decreased physical activity and diet quality. ${ }^{29,}{ }^{30}$ Few studies that have examined diet quality in addition to physical activity and weight. For example, in a study of 159 college students at a public university in the western United States, students who gained $\geq 5 \%$ of their body weight reported less physical activity during their first semester of college compared to what they did in high school compared to those participants who gained $<5 \%$ of their body weight. ${ }^{29}$ As Wengreen et al. ${ }^{29}$ report, this is similar to other studies that found a decrease in physical activity was associated with weight gain risk, even with a decrease in energy intake.

\section{The Current Study}

Although the associations of diet, physical activity, and sleep variables have been examined in some adult samples, ${ }^{31,32}$ these studies typically explore the impact of diet and 
exercise interventions on sleep outcomes. Research studies that have examined sleep, diet and exercise in college students have traditionally focused on athletes and males. Therefore, using the Biopsychosocial Model ${ }^{33}$ (George \& Engel, 1980) as a framework to understand complex health indicators, the current study examines how sleep and physical activity influences diet in college-aged women. It was hypothesized that exercise would mediate the association between sleep quality and diet in college-aged women.

\section{METHODS}

\section{Design, Recruitment and Participants}

This study presents cross-sectional data from a larger study examining the impact of two weight loss interventions on weight status, lipid profile and fitness activity in overweight and obese college females. Participants were recruited from a midsize northeast university via flyers, newspaper advertisements, and class announcements during the academic year. Eligibility criteria were: female, BMI between $25-39.9 \mathrm{~kg} / \mathrm{m}^{2}$. Additional eligibility criteria were self-report of the following: age between 18-24 years, not pregnant or lactating, no diagnosis of coronary heart disease, diabetes, liver or kidney disease, bleeding disorders, or history of an eating disorder. The current study only presents baseline data, due to attrition and small sample size as the post-intervention and follow-up time point. Study staff individually completed the informed consent process as approved by the university’s Institutional Review Board with all potential participants in a private location.

\section{Measures}

The study staff used standard measures to collect data on demographic, descriptive and outcome variables. Participants' height, weight and waist circumference were measured after the participant had voided ${ }^{34}$ and height and weight were used to calculate BMI (weight in 
kilogram/height in meters 2 ). ${ }^{35}$ Body composition was performed using air displacement plethysmography ${ }^{36}$ and percent body fat was obtained using the Brozek equation. ${ }^{37}$ The primary study outcomes of interest were assessed using the standard protocols described below.

Sleep quality was measured using the 19-item Pittsburgh Sleep Quality Index (PSQI). ${ }^{38}$ The PSQI is a standardized self-report measure that assesses quality of sleep and sleep disturbances during the past month, with answers on a 4-point Likert scale. Total scores of the PSQI range from 0 to 21, with scores greater than five suggestive of significant sleep disturbances. Internal consistency in the current sample was adequate $(\alpha=.74)$, similar to other studies of college students and sleep. 4,8

Diet was measured via three non-consecutive 24-hour recalls (one weekend and two weekdays) and the three-day mean was used for analyses. ${ }^{39}$ Trained study staff collected and analyzed dietary intake data using the multiple pass method $^{40}$ in conjunction with the Nutrition Data System for Research software, developed by the Nutrition Coordinating Center (version 2009, University of Minnesota, Minneapolis, MN). The first 24-hour recall was done in person and the remaining two recalls were completed over the phone. Data from the Nutrition Data System for Research were converted to HEI-2005 (HEI) scores to assess diet quality. ${ }^{41,42}$ Diet composition was also compared to federal guidelines

Cardiorespiratory fitness activity, the exercise variable, was measured using the maximal oxygen uptake $\left(\mathrm{VO}_{2 \max }\right)$ on a Marquette Series 2000 treadmill (GE Medical Systems, Milwaukee, WI) using the modified Naughton-Balke protocol. Relative $\mathrm{VO}_{2 \max }$ is expressed as $\mathrm{mL} / \mathrm{kg} / \mathrm{min}$ and absolute $\mathrm{VO}_{2 \max }$ is expressed as $\mathrm{L} / \mathrm{min}$. Each participant's relative $\mathrm{VO}_{2 \max }$ was classified on relative norms for women aged 18-25; very poor (<31.6), poor (31.6-35.4), fair (35.5-39.4), good (39.5-43.9), excellent (44.0-50.1), and superior (>50.1). ${ }^{43}$ 


\section{Statistical Analysis}

Continuous variables are presented as mean \pm standard deviation and categorical data are presented as percentages. Normality of data distribution was checked via skewness and kurtosis and the three primary variables were normally distributed. Collinearity between the three variables was checked. The meditational model was tested using methods proposed by Baron and Kenney. ${ }^{39}$ The Sobel test of Mediation was run as well. All analyses were performed using SPSS version 16.0 .

\section{RESULTS}

\section{Participant Characteristics}

Seventy-three participants signed informed consent, 64 completed baseline assessments, and 55 had data for the three main variables of PSQI, HEI, and $\mathrm{VO}_{2 \text { max. }}$ Reasons for not completing baseline assessments were time constraints $(n=6)$, illness $(n=1)$, and inability to recontact $(\mathrm{n}=2)$. The participants $(n=55)$ were all female, mostly Caucasian $(71 \%)$ and most lived on campus (80\%) (Table 1). The mean BMI $\left(29.2 \mathrm{~kg} / \mathrm{m}^{2}\right)$ is on the borderline of overweight (25$\left.29.9 \mathrm{~kg} / \mathrm{m}^{2}\right)$ and obese $\left(\geq 30 \mathrm{~kg} / \mathrm{m}^{2}\right)$. Mean waist circumference was $90.3 \mathrm{~cm}$, which is higher than the recommended 88 centimeters for females. Participants' macronutrient composition fell within federal guidelines. However, mean intakes of calcium, folate, magnesium, potassium and iron were low while mean sodium intake was more than $175 \%$ of recommended intake.

Participants reported an average of $7.1(\mathrm{SD}=1.4)$ hours of actual sleep at night in the past month, with a range from five to ten hours. Less than half $(41.8 \%)$ had good quality sleep as indicated by a score of $\leq 5$ on the PSQI, with a mean PSQI score of $6.8(\mathrm{SD}=3.5$, range $=1-17)$. The mean HEI total score was $61.5(\mathrm{SD}=13.1)$ with a range of 28.0 to 89.3. Mean relative 
$\mathrm{VO}_{2 \max }$ was $30.3 \mathrm{~mL} / \mathrm{kg} / \mathrm{min}(\mathrm{SD}=5.2$, range $=18.8-41.9)$. The mean relative $\mathrm{VO}_{2 \max }$ is in the poor aerobic capacity category. ${ }^{43}$

No collinearity existed between the three variables of interest. Sleep and exercise showed a small correlation, $r(55)=-.30, p=.02$, as did sleep and diet, $r(55)=-.37, p=.005$, while exercise and diet showed a moderate correlation, $r(55)=.42, p=.002$.

\section{Mediational Analyses}

A mediation model was tested to show the effect of exercise as a mediator between sleep quality and diet (Figure 1). In order to establish mediation according to Baron and Kenny’s ${ }^{44}$ methods, three regression equations were estimated: 1) sleep quality predicting exercise, 2) sleep quality predicting Diet, and 3)sleep quality predicting Diet while controlling for exercise.

As predicted, the hypothesis that exercise mediated the relationship between sleep quality and diet was supported. In the first regression analysis, sleep quality predicted exercise $(\beta=-.32$, $p=.02)$, and accounted for $10 \%$ of the variance. Sleep quality also predicted $\operatorname{diet}(\beta=-.38, p=$ .004 ), accounting for $14 \%$ of the variance. In the mediation model, the relationship between sleep quality and diet became non-significant $(\beta=-.282, p=.064)$ while the effect of exercise on diet was significant $(\beta=.45, p=.001)$, and this model accounted for $32 \%$ of the variance. The Sobel test of mediation was significant $(-2.22, p=.03)$.

\section{DISCUSSION}

The results of the current study indicated that exercise mediated the association between sleep quality and diet in college women. In other words, poor sleep predicted lower rates of exercise, which in turn predicted poorer diet. The link between diet and exercise has been well established, and sleep is often examined as an outcome variable as it pertains to the relationship between these variables. However, this is the first study to identify the important role that sleep 
may play in the health outcomes in college females ${ }^{45}$ Female college students who experience poor sleep quality or quantity may be at increased risk of not exercising or maintaining a healthy diet. Nutrition clinicians who may already address the importance of regular exercise when discussing dietary behavior change may also want to consider addressing sleep and sleep duration in addition to issues that dietitians and nutritionist normally work with in relation to sleep like weight issues related to sleep apnea. ${ }^{46,47}$

Our findings can be interpreted using a behavioral framework, ${ }^{48}$ which explains how sleep might influence exercise and diet within an individual. Adequate sleep quality and quantity have been shown to have direct effects on exercise, ${ }^{27} \operatorname{diet}^{19}$ and appetite-regulating hormones. ${ }^{22}$ Sleep is also critical in promoting sustained energy and the ability to make continuously beneficial lifestyle choices such as engaging in regular physical activity and maintaining a healthy diet. ${ }^{1,4,29}$ One could speculate that college students who are well rested may have more energy and motivation to engage in physical activity and be more invested in maintaining a healthy lifestyle. Increased physical demands and belief in one's ability to live a healthy lifestyle could result in better overall nutrition. College students may prioritize exercise as part of their everyday routine, especially on campuses where athletics and/or healthy living are part of the central mission of the university. College students who regularly exercise may also be more likely to adopt other positive health behaviors, such as healthy eating habits.

Another useful lens through which to understand the impact of sleep on health and wellbeing is the Biopsychosocial Model. Biologically, cellular restoration that occurs during the first few hours of sleep increases strength and fitness. The act of exercising may trigger the body to require specific nutrients to sustain muscle growth, therefore promoting improved diet. ${ }^{49}$ Socially, college aged females who experience good social functioning may be surrounded by 
other peers who are modeling healthy eating as a complement to their exercise regimens. ${ }^{50}$ Psychologically, college aged females who experience good mental health and mood may be more likely to adopt healthy sleep and exercise habits. They may have an increased sense of confidence in their ability to engage in healthy behaviors, including exercise and diet, which is consistent with the action stage of the Transtheoretical Model. ${ }^{48}$ Alternatively, our sample may have experienced the opposite; that is, their sleep problems may have impeded their biological, psychological and social functioning, thus resulting in poorer diet and exercise.

Although our findings supported that exercise mediated the association between sleep and diet, the correlational design of the study limits our ability to determine causation. It is plausible that there is a bi-directional relationship between the study variables. In either scenario, examining how this trifecta of health indicators interact is a useful step in understanding health promotion among college students. This study supports that sleep health should be a focus to promote overall wellness in college females. This is consistent with previous research that recommends addressing diet and sleep together to help drive behavioral change. ${ }^{51}$ However, equally plausible is that clinicians intervening on any variable that the person is motivated to change, will help to increase multiple aspects of health and wellness.

\section{Limitations}

Although the current study presents important and novel information about the effect of exercise on the association between sleep and nutrition, limitations in study design must be noted. First, the use of subjective, self-report measures of sleep and diet limits the validity and reliability of the data. Social desirability bias or difficulty recalling accurate information about one's health habits may account for the low internal consistency in the HEI-2005. Future research should employ objective measures of body movement over time including sleep, such as 
actigraphy, and diet to obtain information about students' health habits. Second, given that the participants comprised overweight and obese college students, and obesity is positively

correlated with sleep disordered breathing disorders such as Obstructive Sleep Apnea, ${ }^{52}$ it is plausible that this sample had more severe sleep issues than the average college student population. ${ }^{53}$ However, given that $41 \%$ of participants reported sleep problems, which is consistent with previous research in this population, ${ }^{8}$ more research would need to be conducted to identify the role and impact of sleep disordered breathing on exercise and diet in young adult populations. Third, due to the cross-sectional nature of the study design, causation cannot be determined. Finally, the statistical power of this study was limited by small sample size and the focus on college women decreases generalizability to college males. In spite of these limitations, this study demonstrates the complex associations between sleep, diet and exercise, also considered the trifecta of health.

\section{Conclusions and Future Directions}

Exercise and nutrition have long been promoted as the most important factors in maintaining a healthy lifestyle. As our findings suggest, however, sleep should also be considered a priority in health and wellness. Striving to achieve adequate exercise, nutrition, and sleep will likely reverberate throughout one's body and mind, decreasing stress and improving physical and psychological well-being. As young adults engage in the additional task of gaining independence and autonomy, they are particularly vulnerable to modified patterns in sleep, physical activity, and diet. Further, previous research has shown that obesity rates increased the most with 18-29 year olds and those with some college education..$^{29}$ Institutions of higher education should consider it a priority to implement interdisciplinary health care teams ${ }^{1,51}$ and programs that support students in getting adequate sleep (e.g., later class times or "quiet" dorms), 
diet (e.g., healthy and affordable menu choices) and exercise (e.g., updated facilities and varied programming). If practitioners can apply these best practices, the younger generation will likely attenuate their likelihood of chronic disease development and burden of disease for themselves and the public. 


\section{References}

1. Golem DL, Martin-Biggers JT, Koenings MM, Davis KF, Byrd-Bredbenner C. An integrative review of sleep for nutrition professionals. Adv Nutr. 2014;5:742-759

2. Promotion OoDPaH. Healthy people 2020. Sleep Health. 2016;2016

3. Mallampalli MP, Carter CL. Exploring sex and gender differences in sleep health: A society for women's health research report. J Womens Health (LarChmt). 2014;23:553-562

4. Lund HG, Reider BD, Whiting AB, Prichard JR. Sleep patterns and predictors of disturbed sleep in a large population of college students. J Adolesc Health. 2010;46:124-132

5. Ludy MJ, Tan SY, Leone RJ, Morgan AL, Tucker RM. Weight gain in first-semester university students: Positive sleep and diet practices associated with protective effects. Physiol Behav. 2018;194:132-136

6. $\quad$ Snyder TD, de Brey C. Digest of education statistics (nces 2017-094). 2018

7. Newman BM, Newman PR. Development through life: A psychosocial approach. . Belmont CA: Wadsworth/Cengage Learning; 2012.

8. Adams SK, Kisler TS. Sleep quality as a mediator between technology-related sleep quality, depression, and anxiety. Cyberpsychol Behav Soc Netw. 2013;16:25-30

9. Orzech KM, Salafsky DB, Hamilton LA. The state of sleep among college students at a large public university. J Am Coll Health. 2011;59:612-619

10. Becker SP, Jarrett MA, Luebbe AM, Garner AA, Burns GL, Kofler MJ. Sleep in a large, multiuniversity sample of college students: Sleep problem prevalence, sex differences, and mental health correlates. Sleep Health. 2018;4:174-181

11. Carskadon MA, Sharkey KM, Knopik VS, McGeary JE. Short sleep as an environmental exposure: A preliminary study associating 5-httlpr genotype to self-reported sleep duration and depressed mood in first-year university students. Sleep. 2012;35:791-796

12. Gaultney JF. The prevalence of sleep disorders in college students: Impact on academic performance. J Am Coll Health. 2010;59:91-97

13. Sharkey KM, Carskadon MA, Figueiro MG, Zhu Y, Rea MS. Effects of an advanced sleep schedule and morning short wavelength light exposure on circadian phase in young adults with late sleep schedules. Sleep Med. 2011;12:685-692

14. Peuhkuri K, Sihvola N, Korpela R. Diet promotes sleep duration and quality. Nutr Res. 2012;32:309-319

15. Brown FC, Buboltz WC, Jr., Soper B. Development and evaluation of the sleep treatment and education program for students (steps). J Am Coll Health. 2006;54:231-237

16. Hirshberg SM, Fernandez PM, Melanson KJ, Dwiggins JL, Dimond ES, Lofgren IE. Dietary sugars predict chronic disease risk factors in college students. Topics in Clinical Nutrition. 2011;26:324334

17. Mihalopoulos NL, Auinger P, Klein JD. The freshman 15: Is it real? J Am Coll Health. 2008;56:531533

18. Deforche B, Van Dyck D, Deliens T, De Bourdeaudhuij I. Changes in weight, physical activity, sedentary behaviour and dietary intake during the transition to higher education: A prospective study. Int J Behav Nutr Phys Act. 2015;12:16

19. Bjorvatn B, Sagen IM, Oyane N, Waage S, Fetveit A, Pallesen S, Ursin R. The association between sleep duration, body mass index and metabolic measures in the hordaland health study. J Sleep Res. 2007;16:66-76

20. Crispim CA, Zimberg IZ, dos Reis BG, Diniz RM, Tufik S, de Mello MT. Relationship between food intake and sleep pattern in healthy individuals. J Clin Sleep Med. 2011;7:659-664

21. St-Onge MP, Mikic A, Pietrolungo CE. Effects of diet on sleep quality. Adv Nutr. 2016;7:938-949 
22. Knutson KL. Does inadequate sleep play a role in vulnerability to obesity? American Journal of Human Biology. 2012;24:361-371

23. Brand $\mathrm{S}$, Gerber $\mathrm{M}$, Beck J, Hatzinger M, Puhse $U$, Holsboer-Trachsler E. High exercise levels are related to favorable sleep patterns and psychological functioning in adolescents: A comparison of athletes and controls. J Adolesc Health. 2010;46:133-141

24. Driver HS, Taylor SR. Exercise and sleep. Sleep Med Rev. 2000;4:387-402

25. Myllymaki T, Kyrolainen H, Savolainen K, Hokka L, Jakonen R, Juuti T, Martinmaki K, Kaartinen J, Kinnunen ML, Rusko H. Effects of vigorous late-night exercise on sleep quality and cardiac autonomic activity. J Sleep Res. 2011;20:146-153

26. Youngstedt SD. Effects of exercise on sleep. Clinics in sports medicine. 2005;24:355-365, xi

27. Brand S, Gerber M, Beck J, Hatzinger M, Puhse U, Holsboer-Trachsler E. Exercising, sleep-eeg patterns, and psychological functioning are related among adolescents. World J Biol Psychiatry. 2010;11:129-140

28. Kahlhofer J, Karschin J, Breusing N, Bosy-Westphal A. Relationship between actigraphy-assessed sleep quality and fat mass in college students. Obesity (Silver Spring). 2016;24:335-341

29. Wengreen HJ, Moncur C. Change in diet, physical activity, and body weight among young-adults during the transition from high school to college. Nutr J. 2009;8:32

30. Nelson MC, Story M, Larson NI, Neumark-Sztainer D, Lytle LA. Emerging adulthood and collegeaged youth: An overlooked age for weight-related behavior change. Obesity (Silver Spring). 2008;16:2205-2211

31. Barnes M, Goldsworthy UR, Cary BA, Hill CJ. A diet and exercise program to improve clinical outcomes in patients with obstructive sleep apnea--a feasibility study. J Clin Sleep Med. 2009;5:409-415

32. Kline CE, Crowley EP, Ewing GB, Burch JB, Blair SN, Durstine JL, Davis JM, Youngstedt SD. The effect of exercise training on obstructive sleep apnea and sleep quality: A randomized controlled trial. Sleep. 2011;34:1631-1640

33. George E, Engel L. The clinical application of the biopsychosocial model. American Journal of Psychiatry. 1980;137:535-544

34. Janssen I, Katzmarzyk PT, Ross R. Body mass index, waist circumference, and health risk: Evidence in support of current national institutes of health guidelines. Arch Intern Med. 2002;162:2074-2079

35. Clinical guidelines on the identification, evaluation, and treatment of overweight and obesity in adults--the evidence report. National institutes of health. Obes Res. 1998;6 Suppl 2:51S-209S

36. Fields DA, Goran MI, McCrory MA. Body-composition assessment via air-displacement plethysmography in adults and children: A review. Am J Clin Nutr. 2002;75:453-467

37. Brozek J, Grande F, Anderson JT, Keys A. Densitometric analysis of body composition: Revision of some quantitative assumptions. Ann N Y Acad Sci. 1963;110:113-140

38. Buysse DJ, Reynolds CF, 3rd, Monk TH, Berman SR, Kupfer DJ. The pittsburgh sleep quality index: A new instrument for psychiatric practice and research. Psychiatry Res. 1989;28:193-213

39. Nelson M, Black AE, Morris JA, Cole TJ. Between- and within-subject variation in nutrient intake from infancy to old age: Estimating the number of days required to rank dietary intakes with desired precision. Am J Clin Nutr. 1989;50:155-167

40. Jonnalagadda SS, Mitchell DC, Smiciklas-Wright H, Meaker KB, Van Heel N, Karmally W, Ershow AG, Kris-Etherton PM. Accuracy of energy intake data estimated by a multiple-pass, 24-hour dietary recall technique. J Am Diet Assoc. 2000;100:303-308; quiz 309-311

41. Landy DC, Kurtz JM, Miller TL, Ludwig DA. Statistical program to automate the creation of healthy eating index scores using nutrition data system for research output. J Acad Nutr Diet. 2012;112:A14 
42. Guenther PM, Reedy J, Krebs-Smith SM, Reeve BB. Evaluation of the healthy eating index-2005. J Am Diet Assoc. 2008;108:1854-1864

43. D'Alonzo KT, Marbach K, Vincent L. A comparison of field methods to assess cardiorespiratory fitness among neophyte exercisers. Biol Res Nurs. 2006;8:7-14

44. Baron RM, Kenny DA. The moderator-mediator variable distinction in social psychological research: Conceptual, strategic, and statistical considerations. J Pers Soc Psychol. 1986;51:11731182

45. Hladkyj S, Marrone S, Robinson-Epp N, Ruthig J. Changes in college student health: Implications for academic performance. Journal of College Student Development. 2011;52:307-320

46. Govers E, Seidell JC, Visser M, Brouwer IA. Weight related health status of patients treated by dietitians in primary care practice: First results of a cohort study. BMC Fam Pract. 2014;15:161

47. Jordan AS, McSharry DG, Malhotra A. Adult obstructive sleep apnoea. Lancet. 2014;383:736-747

48. Prochaska JO. Transtheoretical model of behavior change. New York: Springer; 2013.

49. Pendergast DR, Meksawan K, Limprasertkul A, Fisher NM. Influence of exercise on nutritional requirements. Eur J Appl Physiol. 2011;111:379-390

50. Yakusheva O, Kapinos K, Weiss M. Peer effects and the freshman 15: Evidence from a natural experiment. Econ Hum Biol. 2011;9:119-132

51. Nantsupawat N, Buscemi D, Nugent K, Limas N. Should expanded weight loss counseling include sleep counseling and simple clinical tools for patient assessment? Topics in Clinical Nutrition. 2016;31:178-183

52. Hargens TA, Kaleth AS, Edwards ES, Butner KL. Association between sleep disorders, obesity, and exercise: A review. Nat Sci Sleep. 2013;5:27-35

53. Petrov ME, Lichstein KL, Baldwin CM. Prevalence of sleep disorders by sex and ethnicity among older adolescents and emerging adults: Relations to daytime functioning, working memory and mental health. J Adolesc. 2014;37:587-597 